\title{
Day surgery in Scotland: patient satisfaction and outcomes
}

\author{
John Bain, Hugh Kelly, David Snadden, Harry Staines
}

\begin{abstract}
Objective-To evaluate patients' views on the process and outcome of day surgery in Scotland, and to study patients' satisfaction with care in a range of specific procedures.
\end{abstract}

Design-Questionnaires completed by a census of day case surgery patients within a band of 25 procedures under the umbrella of five broad groups: (1) general surgery; (2) urology; (3) gynaecology; (4) orthopaedics; (5) ear, nose, and throat; ophthalmology

Setting-13 hospitals in six health board areas in Scotland

Subjects-During the period 1995-6, 5069 day case patients were asked to complete a questionnaire within two weeks of their operation and discharge from hospital.

Main outcome measures-Arrangements before admission; immediate postoperative symptoms and complications; problems experienced after discharge; readmission after discharge.

Results-A response rate of $68 \%$ was obtained from 13 sites ranging from $43 \%$ to $82 \%$. The overall satisfaction score was 85. A total of 894 patients (26\%) experienced pain after surgery and $783(23 \%)$ had relatively minor medical problems after discharge. In total, $265(7.8 \%)$ patients were readmitted to hospital after discharge. Few notable differences existed between specialties or hospitals in terms of satisfaction scores, although notable pain was experienced more frequently in gynaecology and general surgery patients. Readmission was more common for urological procedures.

Conclusion-Overall, patient satisfaction with day case surgery was high. Dissatisfaction was largely related to waiting times between admission, operation, and discharge. The amount of pain experienced also had a notable impact on the level of patient satisfaction. Day surgery is not without complications, with $26 \%$ of patients experiencing notable degrees of pain; $23 \%$ having minor medical problems after discharge; and $8 \%$ of respondents having to reattend hospital with problems relating to their original operations. (Quality in Health Care 1999;8:86-91)

Keywords: day surgery; patient satisfaction; complications; outcomes

Correspondence to: Professor J Bain, Tayside Centre for General Practice, University of Dundee, Kirsty Semple Way, Dundee DD2 4AD, UK.

Accepted 19 January 1999

Day surgery in Scotland, in common with the rest of the UK, Europe, and the United States is on the increase. ${ }^{1}$ At the same time, inpatient episodes for the same procedures are decreasing. Day surgery in Scotland has increased by $570 \%$ since 1981 from 53644 to 306080 cases in $1995 .^{2}$ This sharp rise in activity has been a product of advancing medical technology, a better understanding of what can be done safely in one day, and increasing pressure applied to provider units to streamline hospital care.

Several UK studies have been conducted on day surgery. ${ }^{1-7}$ In 1990 , auditors from the audit commission for England and Wales were trained to collect data from 20 common surgical procedures supplemented by interviews taken with consultants, anaesthetists, managers, and nursing staff. This review focused mainly on levels of activity and organisation of care and facilities. ${ }^{1}$ The auditors found that a wide variation of activity existed across districts and that there was a large potential for increased day surgery through a reduction of inpatient procedures. Most hospitals were found to have a dedicated day case ward or a ward with theatres attached to their main day surgery facility with all units situated next to or in a general inpatient hospital. This is different from practice in the United States where standalone units are common. Wide variation was also noted in the structure, design, and layout of day care units.

The main thrust of day surgery appears to be a cost reduction for the purchaser together with a reduction in waiting times and a quicker return to a familiar home environment for the patient. $^{89}$ A report by the NHS taskforce in 1991 highlighted the proposed growth of day surgery to include $50 \%$ of all elective operations by the year 2000. ${ }^{10}$ Guidelines exist for setting up and running day surgery units and targets for acceptable activity. ${ }^{5}$ However, evaluation of day surgery has tended to focus on the hospital perspective, comparing effectiveness and acceptability with traditional inpatient care. ${ }^{1-6}$ The reported benefits for patients include reduced waiting times, booked appointments, and care in dedicated facilities, ${ }^{10-13}$ although caution exists with regard to the perceived benefits. ${ }^{14}{ }^{15}$ There is little published information on patients' experience of day surgery, although the audit commission report highlighted the specific areas of dissatisfaction which included lack of facilities, poor levels of privacy, absence of telephones, poor information, and insufficient warning of admission and discharge. ${ }^{6}$

The objectives of the study reported were to outcome of day surgery in Scotland, and to 
Table 1 List of participating hospitals

\begin{tabular}{lll}
\hline Hospital & Size (beds) & Type of population \\
\hline A & 568 & Market town \\
B & 605 & Inner city \\
C & 450 & Market town \\
D & 379 & Market town \\
E & 334 & Market town \\
F & 607 & Urban and rural \\
G & 328 & Market town \\
H & 183 & Inner city \\
I & 976 & Large city \\
J & 261 & Rural \\
K & 130 & City \\
L & 78 & Rural \\
M & 457 & Urban and rural \\
\hline
\end{tabular}

study patients' satisfaction with care in a range of specific procedures.

\section{Methods}

PROCEDURES

A total of 20 procedures were identified and divided into five broad groups: (1) general surgery, (2) urology; (3) gynaecology; (4) orthopaedics, and (5) ear, nose, and throat (ENT) and ophthalmology were studied and compared with previous work. ${ }^{1}$ As part of the negotiations with participants, five further "procedures" were included in the study. There are 13 health boards in Scotland which are responsible for overall healthcare provision in their areas. Within these boards, hospitals are grouped within NHS trusts which care for defined populations. Thirteen hospitals were recruited from six health board areas and within 12 NHS trusts. Selection was made to ensure representation of small and large hospitals, the amount of day surgery activity, facilities, type of population, and variations in urban/rural location (table 1 ).

\section{QUESTIONNAIRE}

After consultation with all participant providers, and taking account of local circumstances, a modified questionnaire containing specific questions under four broad headings was piloted in three sites and found to be acceptable. To encourage a high response, on admission patients were given a letter of explanation from participating hospitals and a consent form about the study. A questionnaire accompanied by a prepaid return addressed envelope was subsequently distributed to a sample of 5069 patients. A reminder letter and questionnaire were sent to those patients who had not responded within one month after the original questionnaire was distributed.
The questionnaire (complete copies of which are available on request) consisted of both open and closed questions, the key areas being:

- Information (for example, was the patient given enough information?)

- Outcome measures (for example, readmission to hospital)

- Timing of events (for example, time of admission, discharge, or time kept waiting)

- Support services (for example, use of services after discharge, general practice)

The questionnaire was distributed two weeks after discharge and limited to adults over 15 years of age. Using the Audit Commission report sampling methodology, ${ }^{9}{ }^{11} 16$ which reported response rates of $50 \%$, an overall sample size of around 5000 was required to return around 2500 completed questionnaires. Ethical approval was secured and the results were coded to ensure patient confidentiality.

\section{ANALYSIS}

Statistical analysis was by $\chi^{2}$ test for nominal data and two sample $t$ tests for ordinal data where single questions were considered.

Following a review of previous studies, ${ }^{1}{ }^{9} 16$ and from analysis of the pilot study and returned questionnaires, there were many questions which would help to point towards satisfaction. However, three questions in particular gave a strong indication: (1) would the patient undergo day surgery in the future if given the choice? (2) Were they satisfied with the experience of day surgery? (3) If a friend was in need of similar treatment, would they recommend day surgery? To increase the rigour of the concept of satisfaction, patients were only classified as satisfied if they responded positively to all three of these questions. These patients were then compared with various outcome measures, (for example, pain) to determine which experiences had the greatest influence on whether a patient was satisfied with day surgery or not.

\section{Results}

A total of $3408(67 \%)$ of the 5069 questionnaires distributed were returned after one reminder. Responses from different provider units ranged from $82 \%$ to $43 \%$. Of the responses, 1295 (38\%) were from men, 2004 $(59 \%)$ from women, with 109 (3\%) unrecorded; $824(24 \%)$ were from patients aged 15-34, 1157 (34\%) from those aged 35-54, and 1278 (38\%) from those aged over 55 years,

Table 2 Patients'experiences before admission

\begin{tabular}{|c|c|c|c|c|}
\hline \multirow[b]{2}{*}{ Question } & \multicolumn{3}{|l|}{ Responses } & \multirow[b]{2}{*}{$p$ Value } \\
\hline & Yes & No & $\begin{array}{l}\text { Don't know } \\
(\%)\end{array}$ & \\
\hline Was the patient offered a choice of day surgery? & $463 / 535$ & $2030 / 2565$ & 174 & - \\
\hline Satisfaction score & 87 & 79 & - & $\mathrm{p}<0.12$ \\
\hline Did the patient receive written information? & $1597 / 1849$ & $935 / 1120$ & 144 & - \\
\hline Satisfaction score & 86 & 83 & - & $\mathrm{p}<0.03$ \\
\hline Was the patient satisfied with explanations? & $2471 / 2862$ & $100 / 146$ & $102(3)$ & - \\
\hline Satisfaction score & 86 & 68 & - & $\mathrm{p}<0.000$ \\
\hline $\begin{array}{l}\text { Did the patient understand that day surgery meant no } \\
\text { overnight stay? }\end{array}$ & $2523 / 2934$ & $42 / 63$ & 111 & - \\
\hline Satisfaction score & 86 & 67 & - & $\mathrm{p}<0.000$ \\
\hline
\end{tabular}


Table 3 Experiences after operation

\begin{tabular}{|c|c|c|c|c|c|}
\hline \multirow[b]{2}{*}{ Question } & \multicolumn{3}{|l|}{ Responses } & \multirow[b]{2}{*}{ Total } & \multirow[b]{2}{*}{$p$ Value } \\
\hline & Yes $(\%)$ & No $(\%)$ & Don't know (\%) & & \\
\hline Did patient have enough warning before discharge? & $3050(89)$ & $172(5)$ & $186(6)$ & 3408 & \\
\hline Satisfaction score & 87 & 58 & - & - & $\mathrm{p}<0.01$ \\
\hline${ }^{\star}$ Pain experienced in 24 hours after discharge? & $894(26)$ & $2391(70)$ & $123(4)$ & 3408 & \\
\hline Satisfaction score & 68 & 89 & & & $\mathrm{p}<0.01$ \\
\hline Medical problems after operation? & $783(23)$ & $2569(75)$ & $56(2)$ & 3408 & \\
\hline Satisfaction score & 82 & 85 & - & - & $\mathrm{p}<0.05$ \\
\hline Reattendance to hospital (within 24 hours) & $265(8)$ & $3101(91)$ & $42(1)$ & 3408 & \\
\hline Satisfaction score & 81 & 86 & - & - & $\mathrm{p}<0.05$ \\
\hline
\end{tabular}

*Yes response categorised as pain greater than "a little".

with 149 (4\%) unrecorded. 439 of the patients (13\%) lived alone with 149 (4\%) unrecorded. The $\chi^{2}$ goodness of fit test ${ }^{23}$ showed that the observed frequencies were consistent with equal response rate $\left(\chi^{2}(8)=1.38 ; \mathrm{p}=0.99\right)$.

Only $580(17 \%)$ patients were offered the choice between day surgery and inpatient care, but there was no significant difference in overall satisfaction score between those offered the choice (score 87) and those not $2664(78 \%)$ (score 85$)\left(\chi^{2}(1)=2.68 ; \mathrm{p}=0.10\right)($ table 2$)$.

There was significant difference $\left(\chi^{2}(1)=4.64 ; \mathrm{p}=0.03\right)$ in satisfaction scores between the 1942 patients $(57 \%)$ who received written information about procedures before admission (score 86) and the 1322 (39\%) who did not (score 83). There was also a significant difference $\left(\chi^{2}(1)=35.6 ; \mathrm{p}<0.0005\right)$ between satisfaction scores for $3131(92 \%)$ patients who considered everything had been adequately explained (score 86) and 175 (5\%) who did not consider explanation was adequate (score 68 ). The amount of privacy experienced by the patient had a direct bearing upon their satisfaction, with those experiencing less than acceptable privacy $(n=150,4 \%)$ being significantly less satisfied (score 68$)\left(\chi^{2}(1)=47.1\right.$; $\mathrm{p}<0.0001$ ).

WAITING TIMES

Waiting times were important to patients, with those who thought they were kept waiting longer than expected less satisfied, 460 (13\%) (score 71), than those who thought they were waiting as expected, 2791 (82\%) (score 86). Timing between admission and discharge was related to satisfaction scores, with a significant difference being evident among those admitted early and discharged early (scores 88 and 87) and those admitted and discharged at a later time (scores 80 and 68$)\left(\chi^{2}(5)=11.45 ; p=0.04\right.$ and $\chi^{2}(4)=13.63 ; \mathrm{p}=0.0086$, respectively).

A total of 3050 patients $(89 \%)$ considered that they had received sufficient warning about the timing of their discharge (score 87) (table 3). The 172 patients who thought they were not given enough warning about discharge had a significantly lower satisfaction score of 58 $\left(\chi^{2}(1)=82.5 ; \mathrm{p}<0.0001\right)$.

Having someone to contact if a problem arose after discharge was seen as important for the majority of patients. Those given a contact were more satisfied ( $n=2582,76 \%)$ compared with those that had not $(\mathrm{n}=681,20 \%)$ (score 83) $\left(\chi^{2}(1)=9.13 ; p=0.0025\right)$. In total, 3033 $(89 \%)$ patients had someone to escort them home after their operation and 2590 (76\%) ensured that someone stayed with them, for at least the first night after surgery. In total, 176 $(13 \%)$ patients indicated a preference to have remained in hospital after the operation.

A total of $645(19 \%)$ recounted a "fair amount" of pain and $249(7 \%)$ "a lot of pain" after day case surgery. This group of $894(26 \%)$ patients had a satisfaction score of 68 which was significantly lower $\left(\chi^{2}(1)=61.8 ; \mathrm{p}<0.0001\right)$ than the $2391(70 \%)$ patients who had "little" or "no pain" (score 89) (table 3).

Patients were less satisfied if they experienced unexpected pain compared with patients who had pain but had expected it. This was particularly true of gynaecology and general surgery day case patients. In gynaecology, patients experiencing pain which they had expected had a satisfaciton score of 85 , while those with unexpected pain had a satisfaction

Table 4 Medical problems after discharge

\begin{tabular}{|c|c|c|c|c|c|c|c|}
\hline & \multicolumn{7}{|c|}{ Breakdown by provider } \\
\hline & $1(\%)$ & $3(\%)$ & $5(\%)$ & $7(\%)$ & $9(\%)$ & $11(\%)$ & Total (\%) \\
\hline Yes & $103(33)$ & $76(22)$ & $44(32)$ & $74(19.8)$ & $50(24)$ & $58(17.2)$ & $783(23)$ \\
\hline No & $200(65)$ & $277(78)$ & $75(54)$ & $297(79)$ & $146(71)$ & $278(82)$ & $2570(75)$ \\
\hline Not coded & $5(2)$ & 0 & $19(14)$ & $2(0.6)$ & $10(5)$ & $1(0.3)$ & $55(2)$ \\
\hline \multirow[t]{3}{*}{ Total } & 308 & 353 & 138 & 373 & 206 & 337 & 3408 \\
\hline & \multicolumn{7}{|c|}{ Breakdown by specialty groupings (for 20 procedures) } \\
\hline & $1(\%)$ & $2(\%)$ & $3(\%)$ & $4(\%)$ & $5(\%)$ & Totals (\%) & \\
\hline Yes & $49(24.1)$ & $183(20.5)$ & $189(33.3)$ & $34(10.5)$ & $48(13.6)$ & $503(23.1)$ & \\
\hline No & $154(75.9)$ & $709(79.5)$ & $379(66.7)$ & $132(79.3)$ & $305(86.4)$ & $1679(76.9)$ & \\
\hline Totals & 203 & 892 & 568 & 166 & 353 & 2182 & \\
\hline
\end{tabular}

Specialty groupings:

(1) general surgery; (2) urology; (3) gynaecology; (4) orthopaedics; (5) ENT; ophthalmology

Breakdown by provider: the 13 providers have been grouped into the 12 trusts they serve. The figures given include five other procedures outwith the 20 selected for review. The specialty grouping tables only show results for the 20 selected procedures. 
Table 5 Readmission to hospital after day surgery

\begin{tabular}{|c|c|c|c|c|c|c|c|c|c|c|c|c|}
\hline & \multicolumn{12}{|c|}{ Breakdown by provider } \\
\hline & $1(\%)$ & $2(\%)$ & $3(\%)$ & $4(\%)$ & $5(\%)$ & $6(\%)$ & $8(\%)$ & $9(\%)$ & $10(\%)$ & $11(\%)$ & $12(\%)$ & Total (\%) \\
\hline Yes & $12(3.9)$ & $12(4.0)$ & $14(4.0)$ & $15(4.1)$ & $6(4.3)$ & $16(4.6)$ & $6(5.4)$ & $12(5.8)$ & $11(5.8)$ & $62(18.4)$ & $81(21.1)$ & $265(7.8)$ \\
\hline No & $291(94)$ & $288(96)$ & $339(96)$ & $344(95)$ & $132(96)$ & $327(94)$ & $100(89)$ & $184(89)$ & $178(93)$ & $274(81)$ & $291(76)$ & $3101(91.0)$ \\
\hline Not coded & $5(1.6)$ & 0 & 0 & $3(0.8)$ & 0 & $3(0.9)$ & $6(5.4)$ & $10(4.9)$ & $1(0.5)$ & $1(0.3)$ & $11(2.9)$ & $42(1.2)$ \\
\hline \multirow[t]{3}{*}{ Total } & 308 & 300 & 353 & 362 & 138 & 346 & 112 & 206 & 190 & 337 & 383 & 3408 \\
\hline & \multicolumn{12}{|c|}{ Breakdown by specialty groupings (for 20 procedures) } \\
\hline & $1(\%)$ & $2(\%)$ & $3(\%)$ & $4(\%)$ & $5(\%)$ & Total (\%) & & & & & & \\
\hline Yes & $10(4.9)$ & $\begin{array}{l}121 \\
(13.6)\end{array}$ & $38(6.7)$ & $8(4.8)$ & $14(4.0)$ & $\begin{array}{l}191 \\
(8.8)\end{array}$ & & & & & & \\
\hline No & $\begin{array}{l}193 \\
(95.1)\end{array}$ & $\begin{array}{l}771 \\
(86.4)\end{array}$ & $\begin{array}{l}530 \\
(73.3)\end{array}$ & $\begin{array}{l}158 \\
(95.2)\end{array}$ & $\begin{array}{l}339 \\
(96.0)\end{array}$ & $\begin{array}{l}1991 \\
\quad(91.2)\end{array}$ & & & & & & \\
\hline Totals & 203 & 892 & 368 & 166 & 353 & 2182 & & & & & & \\
\hline
\end{tabular}

Specialty groupings: (1) general surgery; (2) urology; (3) gynaecology; (4) orthopaedics; (5) ENT; ophthalmology.

Breakdown by provider: the 13 providers have been grouped into the 12 trusts they serve. The figures given include five other procedures outwith the 20 selected for review. The specialty grouping tables only show results for the 20 selected procedures.

score of $66\left(\chi^{2}(1)=22.7 ; \mathrm{p}<0.005\right)$. In general surgery, patients with expected pain had a satisfaction score of 75 compared with those with unexpected pain whose satisfaction score was $69\left(\chi^{2}(1)=6.40 ; p=0.011\right)$. The differences in satisfaction were not notably different in patients undergoing procedures in urology; orthopaedics; ENT; and ophthalmology.

Table 4 gives details of medical problems after discharge by provider unit and by specialty. A total of $783(23 \%)$ respondents described "medical problems" after day case surgery, the majority being of a relatively minor nature. The most common were wound infection $(41 \%)$, bleeding $(15 \%)$, or allergy $(5 \%)$. Satisfaction scores for these groups were significantly lower (score 82 ) than for patients who experienced no such problems (score 86) $\left(\chi^{2}(1)=9.77 ; \mathrm{p}=0.0018\right)$. Within specialties, patients with gynaecological problems had a notably higher percentage $(33.3 \%)$ of medical problems than other specialties which was reflected in their satisfaction score of 74 . By way of contrast, 113 of ENT and ophthalmology patients had medical problems and a satisfaction score of 85 .

Feeling physically sick had a marked influence on the outcome of patients' experience of day surgery, with those patients who were not sick $(n=2872,84 \%)$ being significantly more satisfied (score 88) than those who were sick $(\mathrm{n}=536,16 \%) \quad($ score 75$) \quad\left(\chi^{2}(1)=48.6\right.$; $\mathrm{p}<0.0001)$. Patients' return to normal function includes the ability to do normal activities such as bathing, climbing stairs, shopping, and lifting. The mean time to recovery of those patients satisfied with day surgery was 4.4 days, which is significantly shorter than those who were dissatisfied, who took on average 5.5 days to recover $(t(426)=2.67 ; \mathrm{p}<0.0030)$.

\section{Hospital readmission/reattendance}

In the questionnaire, patients were asked if they had unplanned hospital readmission or reattendance within 24 hours of discharge. Table 5 shows the results of reattendance by provider unit and by specialty. A total of 265 patients ( $7.8 \%$ of respondents) indicated that they had unplanned reattendance for a problem relating to their operation. Ten of the provider units had readmission rates of between 4 and $6 \%$, but two of the providers had rates of $18 \%$ and $21 \%$, respectively.

The satisfaction score for patients reattending hospital was 81 which was significantly less than the satisfaction score of 86 for those not having to reattend $\left(\chi^{2}(1)=4.48 ; \mathrm{p}<0.034\right)$. Although there is a variation in readmission rates, we have no information about readmission for non-respondents, and the study population did not include all day case surgery procedures.

Within specialties, urology (13.6\%) had the highest percentage of patients who required readmission with 24 hours of their original operation, ENT and ophthalmology having the lowest proportion (4\%) of readmissions.

\section{Discussion}

This study shows that patients were largely satisfied with the care they received with an overall satisfaction score of $85 \%$, irrespective of type of operation. Although variations in the response rates from different provider units existed, the overall response rate of $68 \%$ was considered satisfactory, given that three of the provider units had response rates of less than $60 \%$. It was worth noting that these three units were in large urban based centres. Satisfaction scores are difficult to interpret when considering relatively minor operative procedures where, with a careful selection policy, it would be surprising if the large majority of patients did not have satisfactory outcomes. In 1991 the Audit Commission for England and Wales revealed that the majority of day case surgery patients were satisfied with their treatment and that the proportion who were dissatisfied were similar to that for inpatients. ${ }^{11}$

Patient satisfaction has also to be considered in the context of the limitations of surveys using questionnaires. ${ }^{17}$ Virtually all surveys indicate only a few patients who expressed negative views about their care, with at least $80 \%$ of respondents usually expressing satisfaction for any given question. ${ }^{18}$ This may be due to a reluctance by patients to express criticisms of the NHS. ${ }^{19}$

Although most patients were satisfied with the care given, the results have revealed areas requiring review by providers if patient satisfac- 
tion is to remain high as day surgery expands. Patients often forget about information given verbally, ${ }^{20}$ but our results indicate that providing too much complex information can be just as confusing. We found a significant difference in satisfaction between those who considered adequate written and verbal explanation had been received and those who did not. Clear written instructions combined with good verbal explanations may reduce patient misunderstanding. Although attention has been given to waiting times between diagnosis and admission, ${ }^{21}$ little attention has been paid to waiting times during admission and up to discharge. The results revealed a significant number of patients dissatisfied with the time between admission to hospital and the actual operation, highlighting the need for an effective communication strategy to ensure that patients know what to expect. ${ }^{22}$

Successful outcomes in day surgery depend on careful selection of patients, careful surgery, and careful anaesthetic. ${ }^{23}$ Our study has showed that one in four patients (of those who responded to the questionnaire) experienced some medical problems after day case surgery ranging from slight bleeding to being readmitted to hospital. Although the majority of these problems were relatively minor, our results have shown that it would be wrong to assume that day case surgery has no implications for patients' ongoing care. ${ }^{24}$ There were notable differences between specialties for medical problems after discharge, with patients undergoing gynaecological procedures having the highest rate. This was reflected in the fact that the patients were also less satisfied, indicating that they have to be adequately forewarned about potential problems on returning home. There were variations between provider units, and it is our hope that the feedback to these units will have an impact on outcomes. At the very least, patients should be informed about potential complications, however minor they may be.

Although facilities to ensure that there is a well organised throughput of patients is important, careful consideration must be given to expected complications and the methods of minimising readmission. Readmission rates of between 1 and $2 \%$ have been suggested as acceptable,${ }^{11}$ but variations in readmission are probably due to various factors including unit policies, type of specialty, age of patients, and the level of primary care support available. In our study, unplanned reattendance or readmission was, on average, $7.8 \%$ and it could be argued that a readmission rate of around 1 in 13 patients is too high. In the absence of any "gold standard" for readmission it is difficult to decide what is an unacceptable level. Our results can merely highlight the range between units and specialties, and the numbers within these groups are not sufficiently large to analyse in any depth the underlying reasons for readmission. However, two of the provider units had readmission rates of $18 \%$ and $21 \%$, and patients undergoing urology procedures were much more likely to be readmitted than other specialties. Again, the response of pro-
Key messages

- To improve communication, patients need to be well informed at all stages of their care

- To avoid dissatisfaction and patient anxiety, patients should be given realistic explanation of pain to be expected

- Twenty three per cent of patients experiences minor medical problems after their operation. Steps need to be taken to communicate the possibility of such complications to patients and those involved in providing care after discharge

- Among respondents, readmission after day surgery was $7.8 \%$ with levels ranging from $4 \%$ to $21 \%$. Providers should examine their discharge policy and find out if patients have sufficient recovery time before discharge

- The majority of patients were satisfied with services received as a day patient

vider units to these findings will be extremely important in assessing quality of care. If 10 of the units could achieve readmission rates of between 4 and $6 \%$, then those with substantially higher rates need to review their selection and management of day cases. Following up trends in readmission rates will be an essential component of any continuing review of standards of day case surgery. It is also worth noting that the results described only relate to readmission for those who responded to our questionnaire, and do not take account of nonrespondents or readmission rates for other procedures done as day cases.

In Scotland, day case surgery currently accounts for a quarter of inpatient operations. It is viewed as an efficient way of maximising the use of resources and avoiding unnecessary stays in hospital. Despite a high level of patient satisfaction, consideration needs to be given to more effective methods of communication between patients and day surgery units about waiting times, pain relief, and anticipated problems after discharge. Although the majority of medical problems after discharge were minor, they still affected one in four patients. Further scrutiny is required of the readmission rates in certain units where the levels are substantially higher than in other centres.

We would like to thank everyone at the participating hospitals without whose cooperation and assistance the study could not have been done. We are grateful to staff at the information and statistics division of the Common Services Agency for providing statistical information about day surgery activity in Scotland.

The project was funded by the Clinical Resources and Audit Group, Department of Health, the Scottish Office.

1 The Audit Commission for England and Wales. A short cut to better services: day surgery in England and Wales. London: HMSO, 1990

2 Common Services Agency. Day case and in-patient discharges 1989-1995. Edinburgh: Information and Statistics Division, The Scottish Office, 1996.

3 Ruckley CV, Cuthbertson D, Fenwick N, et al. Day care after operations for hernia or varicose veins: controlled trial. Br F Surg 1978;65:459-9.

4 Goulbourne IA, Ruckley CV. Operations for hernia and Goulbourne IA, Ruckley CV. Operations for hern
varicose veins in a day bed unit. BMf 1979;2:714.

5 Royal College of Surgeons of England. Guidelines for day case surgery. London: Royal College of Surgeons, 1992. 
6 Audit Commission. Measuring quality: the patients view of day surgery. London: HMSO 1991.

7 Cooper JM. Day case cataract surgery in the UK and USA: a comparative study. Br ₹ Nurs 1997;6:39-43.

8 Ralphs D, Glenister H, Lowry EM, et al. Audit of the practice of day surgery. Royal College Surgeons of England and The

9 Black N, Petticrew M, Hunter D, et al. Day care surgery: development of a national comparative audit service. Quality in Heatlh Care 1993;2:162-6.

10 Department of Health. Day surgery, making it happen. London: DoH, 1991

11 Audit Commission. All in a day's work: an audit of day surgery in England and Wales. London: HMSO 1992.

12 Scottish Office Audit Unit. Day surgery in Scottish hospitals. Edinburgh: Scottish Office, 1992.

13 MacPherson I, Hagen S. Day surgery practice in Scotland: a summary report. London: Health Service Research Unit, summar.

14 Haworth EA, Balarajan R. Day case surgery: does it add or replace inpatient surgery. $B M F$ 1987;294:135.

15 Senapati A, Young AE. Acceptability of day care surgery. $\mathcal{F} R$ Soc Med 1989;82:735-6.
16 Black N, Sanderson C. Development of a questionnaire for eliciting patients experience. Quality in Health Care 1993;2: eliciting

17 Carr-Hill RA. The measurement of patient satisfaction. $f$ Public Health Med 1992;14:236-49.

8 Fitzpatrick R. Surveys of patient satisfaction: important general considerations. BMF 1991;302:887-9.

9 Fitzpatrick R, Hopkins A. Problems in the conceptual framework of patient satisfaction research. Sociology of Health and Illness 1983;5:297-311.

20 Inglis A, Daniel M. A survey of information supplied to day case patients. Health Bulletin 1995;53:91-3.

21 Hitchcock M, Ogg TW. A quality assurance initiative in day case surgery: general considerations. Ambulatory Surgery 1994;2:181-92.

22 De-Jesus G, Abbot S, Collins B, et al. Day surgery: results of a patient satisfaction survey. Quarterly Clinical Practice 1966;16:165-73.

23 Johnson CD, Jarrett PEM. Admission to hospital after day case surgery. Ann R Coll Surg Engl 1990;72:225-8.

24 Pill R, Stott N. An investigation of the impact on general practitioners and community services of increased day surgery. Cardiff: University of Wales College of Medicine, 1995. 